\title{
Physical Modeling of Landward Scour Due to Tsunami Bore Overtopping Seawall
}

\author{
Raidan Maqtan ${ }^{1 *}$, Badronnisa Yusuf ${ }^{2}$, and Saiful Bahri Hamzah ${ }^{3}$ \\ ${ }^{1}$ Master student at University Putra Malaysia, works lecturer assistant at Civil Engineering \\ Department, University of Aden, Yemen. \\ ${ }^{2}$ Senior Lecturer at Civil Engineering Department, University Putra Malaysia, Serdang, Malaysia. \\ ${ }^{3} \mathrm{PhD}$ Student at University Putra Malaysia, Civil Engineering Department, Serdang, Malaysia, Works \\ at National Hydraulic Research Institute of Malaysia (NAHRIM).
}

\begin{abstract}
. many of the post tsunami field surveys which conducted by researchers revealed that, the failure due to scour at the landward toe of the seawall due to overtopping of tsunami wave forms one of the important types of coastal defence structures failure and constitutes one of the biggest threats to their structural performance. This study was intended to investigates the scour profile induced by tsunami bores at the landward toe of the vertical seawall and to discuss the effects of the parameters; tide level, incident bore Froude number $\mathrm{Fb}$, incident bore height $\mathrm{Hb}$, overtopping flow Froude number Fo, and overtopping flow depth Ho on the maximum scour depth induced at the landward toe of the seawall. A set of laboratory experiments were conducted at National Hydraulic Research Institute of Malaysia (NAHRIM) with the tichnique of dam break to generate the bore like tsunami. The experiments showed that the initial water level upstream of the seawall has a significant effect on the scour profile and there is a strong negative relationship exists with Froude number of the incident bore and a strong positive relationship exists with Froude number of the overtopping flow depth above the crest of the seawall.
\end{abstract}

\section{Introduction}

Protection or mitigation processes from tsunamis disasters still an open question and considered as one of the important challenges confront the engineers and researchers. Since the Chilean tsunami in 1960 and the disaster of storm surge induced by typhoon in 1953, the concrete seawall and armored dikes have been constructed in Japan. Seawalls and dikes failure mechanisms due to tsunami have not yet been fully understood [1]. Physical modeling, numerical modeling, and post tsunami field surveys are common applied methods to investigate the local effects of tsunami waves [2]. Around two decades ago there were three famous tsunamis disasters happened worldwide "the 2004 Indian Ocean

\footnotetext{
* Corresponding author: ridan76@yahoo.com
} 
tsunami, the 2010 Chile tsunami, and the 2011 Tohoku tsunami" caused a large loss of lives and destructions of surrounding environments [3]. These tsunamis followed by many post disaster field studies have been conducted by researchers and revealed that, the most cause of failure of the coastal dikes and seawalls was the scour at the landward toe induced by tsunami overtopping.

The main objectives of this laboratory study are to investigate the scour depth generated at the landward toe of the seawall due to tsunami bore, and to discuss the effects of tsunami bore parameters on the maximum scour depth. The physical model was designed in appropriate scale, the dam break technique was used to generate the bore like tsunami bore, and the experiments were conducted based on three different hydraulic conditions. The experiments showed that, there is a significant effect of the initial water depth upstream of the wall on the scour profile at the landward toe of the seawall, and further studies are required to indicate that, the Froude number of incident and overtopping bore can be used as one of the important parameters to predict the maximum scour depth induced by tsunami at the landward toe of the seawall.

\section{Tsunami wave characteristics}

To generate a reasonable wave like tsunami at the laboratory it is important to know a good background about some basics of tsunami wave characteristics and methods of wave generation. Tsunami considered as a long wave by comparing with the ocean depth as its wave period is much larger than the standard gravity wave [4]. It moves shoreward in the form of fast rising tide or may be broken as a bore flooding all things in its path and producing a very large destruction. Through the Indian Ocean Tsunami 2004, the flow velocities which recorded by videos in many zones and by fields survey estimations were 6 to 8 meters per second at Khao Lak, and 3 to 4 meters per second at Kamala Beach in Thailand, and the calculated peak velocity from the videos at Aceh, Sumatra, was mostly 5 $\mathrm{m} / \mathrm{s}[5]$.

The maximum water levels of tsunami observed in Miyako, Ayukawa, and Soma points were $8.5 \mathrm{~m}, 8.6 \mathrm{~m}$, and $9.3 \mathrm{~m}$ respectively during the 2011 Tohoku Earthquake Tsunami eastern of Japan as stated by Japanese Cabinet Office (JCO), 2011 [2]. To study tsunami resilience, it is important to understand risk, assess how systems respond to the built environment, and predict the recovery of infrastructure systems. Surveys of disasters against the built environment highlighted the need for strategies to increase the ability of communities to prepare for future tsunamis and to minimize structural damage and losses [3].

\section{Landward scour induced by tsunami}

A comprehensive field study was conducted by Shimozono and Sato [6] after the 2011 Tohoku tsunami in Japan focused on concrete armored levees failure by local scouring at the toe of the landward slope that was observed widely. They concluded that the breaching at the landside toe of the concrete-armored levees was mainly caused by a severe scouring. Kato et al. [1] conducted a field surveys on coastal dike failure in Iwate, Miyagi, and Fukushima Prefectures between March and May 2011. Their measurements included the tsunami heights near the shoreline and the shape of collapsed coastal dikes. Officially recorded data were obtained on dike and tsunami height for each coast where the tsunami surged over the coastal dike between Aomori Prefecture and Chiba Prefecture. They found that the failure due to scouring at the landward toe was the dominant failure type with a percentage of $49.2 \%$ and the rest percentages are due to other failure patterns. 
Jayaratne et al. [7] conducted a series of laboratory experiments to study the scour depth and length behind the model coastal dike. They prepared drawings of scouring profile behind the model coastal dike for three different wall geometry with three cases of initial water depths upstream of the seawall. They suggested that there is a strong positive relationship exists between the slope angle of the seawall at the landward side and the location of the maximum scour depth with higher correlation factor.

\section{Experimental details and setup}

To add different hydraulic conditions in generating the bore like tsunami, three different initial seaward water depths (upstream of the seawall or downstream of the gate, hd) were adopted. The experiments were numbered from T1 to T3 with detailed conditions for all tests arranged as shown in Table 1 with three runs repetition for each experimental conditions.

Table 1. Tests details and conditions

\begin{tabular}{|c|c|c|c|}
\hline Test & $\begin{array}{c}\text { hu } \\
(\mathrm{m})\end{array}$ & $\begin{array}{c}\text { hd } \\
(\mathrm{m})\end{array}$ & Conditions \\
\hline T1 & 0.6 & 0.1 & low depth /high freeboard \\
\hline T2 & 0.9 & 0.15 & medium depth / medium freeboard \\
\hline T3 & 1.2 & 0.2 & high depth / low freeboard \\
\hline
\end{tabular}

The symbols hu and hd shown in Figure 1 represent the water levels upstream and downstream of the gate respectively immediately before opening the gate to generate the bore like a tsunami.

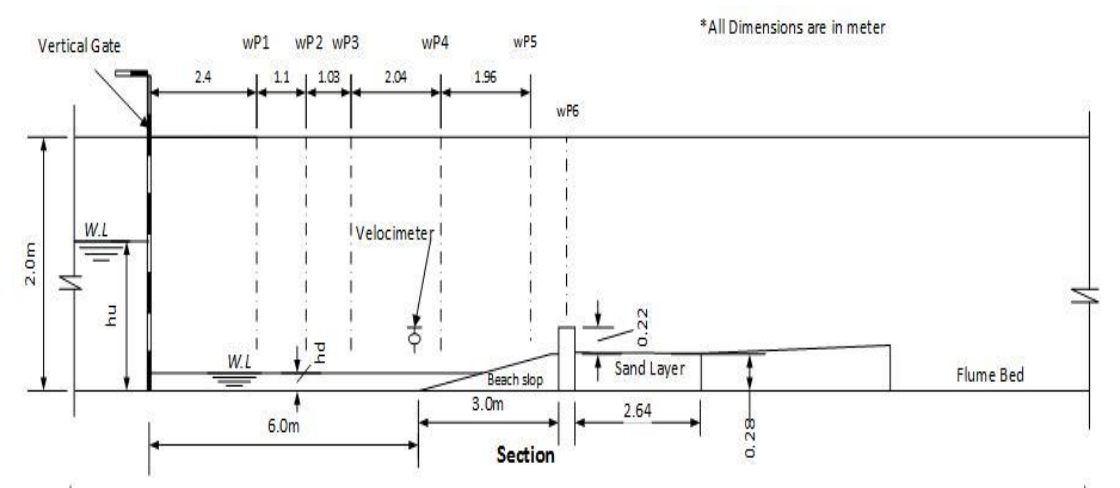

Fig. 1. Experimental setup schematic drawing

All laboratory experiments were conducted in a wave flume at National Hydraulic Research Institute of Malaysia (NAHRIM). The overall dimensions of the flume are $100 \mathrm{~m}$ length, $1.5 \mathrm{~m}$ width and $2.0 \mathrm{~m}$ height. The flume is provided with a glass wall at one side and two techniques of wave generation, one of them is dam break technique and the other is piston type wave generation. In this study dambreak wave generation technique was used to generate the bore like tsunami. Electrically controlled vertical gate located at $45 \mathrm{~m}$ from the back end of the flume was used to produce an appropriate head difference to generate bore like tsunami by sudden opening. The model designed with a scale factor $\operatorname{Lr}$ of 1:20 $(\mathrm{Lr}=\mathrm{Lp} / \mathrm{Lm})$ adopted to achieve the geometric similarities, where $\mathrm{Lp}$ is the dimension in 
prototype scale and $\mathrm{Lm}$ is the corresponding dimension in model scale, and the Froude scaling was used to calculate the flow velocities in prototype scale (i.e. $v_{p}=v_{m} \sqrt{L_{r}}$ ).

A vertical wall model of $0.5 \mathrm{~m}$ total height fixed in position as shown in Figure 1 . The clear height of the seawall above the sand bed level was fixed in the model equal to $0.22 \mathrm{~m}$ ( $4.4 \mathrm{~m}$ in prototype scale). A foreshore beach slope of 1:10 constructed and finished by cement mortar in front of the seawall. A layer of sand especially representing beach material was provided downstream of the seawall (landward) of thickness $0.28 \mathrm{~m}$ and $2.64 \mathrm{~m}$ length (more than the expected maximum scour depth and length). Two perforated drain pipes were laid on the bed of the flume beneath the sand layer to drain water. A grid of spacing $5 \mathrm{~cm}$ in vertical and horizontal directions constructed on the side wall glass to help in checking and visualizing the scour profile. A typical scour profile photo obtained from the experiments is shown in Figure 2.

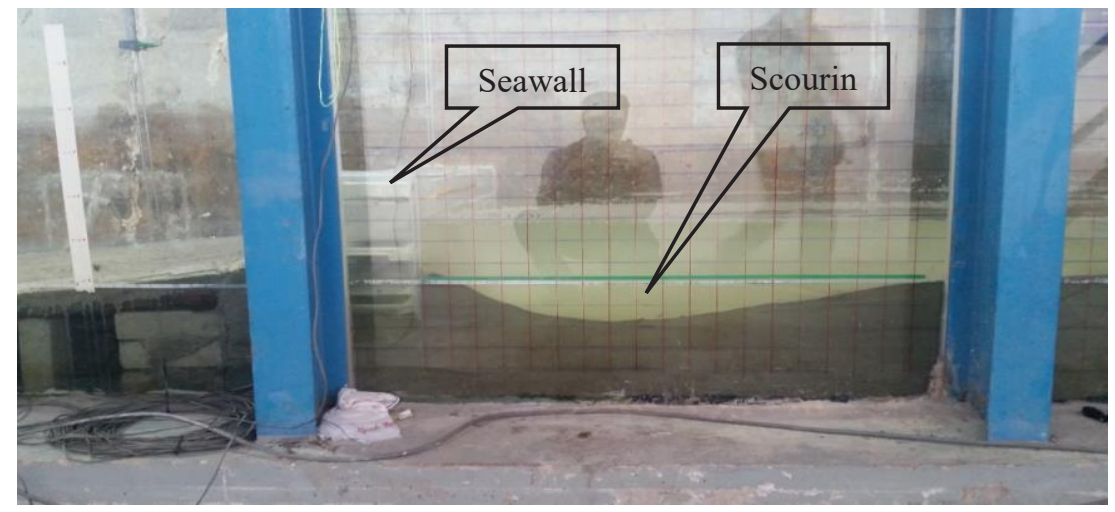

Fig. 2. Typical scour profile

\section{Instrumentation and procedures}

To measure the water surface elevations and bore height, six wave gauges were installed at selected locations as shown in Figure 1. The wave gauges were numbered from WP1 until WP6, where the name WP1 represents the wave probe number 1 . The typical graph shape obtained from the wave gauges is shown in Figure 3 for wave gauge WP4. The right portion of the graph enclosed by dotted square represents the backflow generated after the incident bore hits the seawall. 


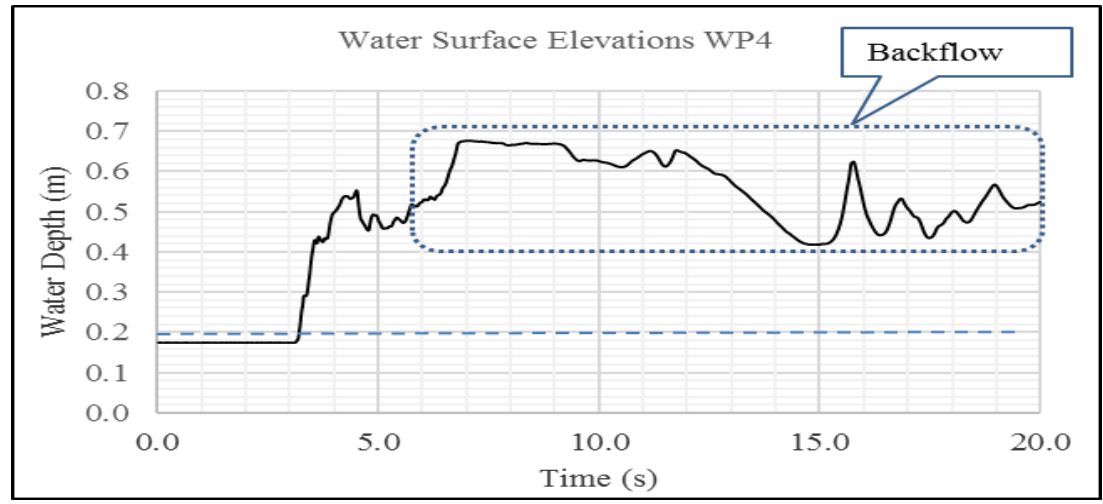

Fig. 3. Water Surface elevations

The bottom elevation of WP4 sensor was $17.0 \mathrm{~cm}$ from the flume bed level and the dotted line in the graph represents the initial water level downstream of the gate $h_{d}$, where in this case (high depth / low freeboard) is equal to $20 \mathrm{~cm}$. For more understanding and confirming the data obtained by the wave gauges, videos at two different locations were recorded to see the stages of water levels and allow for slow motion and repetition. One of the two locations selected for video records was in front of WP4 and WP5 to help in checking the incident bore height, and near this location, the velocimeter (Vectrino) was also provided to appear in the recorded videos.

The graph in Figure 3 was read and checked in conjugate with the video recorded at WP4. A graduated tape was fixed on the glass wall of the flume at the location of WP4, WP5, and the seawall to help in more understanding of the recorded videos. The flow velocity was recorded at two different locations. Vectrino device was installed to measure the incident bore velocity changes with time located immediately at the beginning of the beach slope, and a current meter device located at the top of the seawall to measure the maximum overtopping velocity. The current meter device was fixed in position as shown in Figure 4 in front of the camera to allow for reading from the videos.

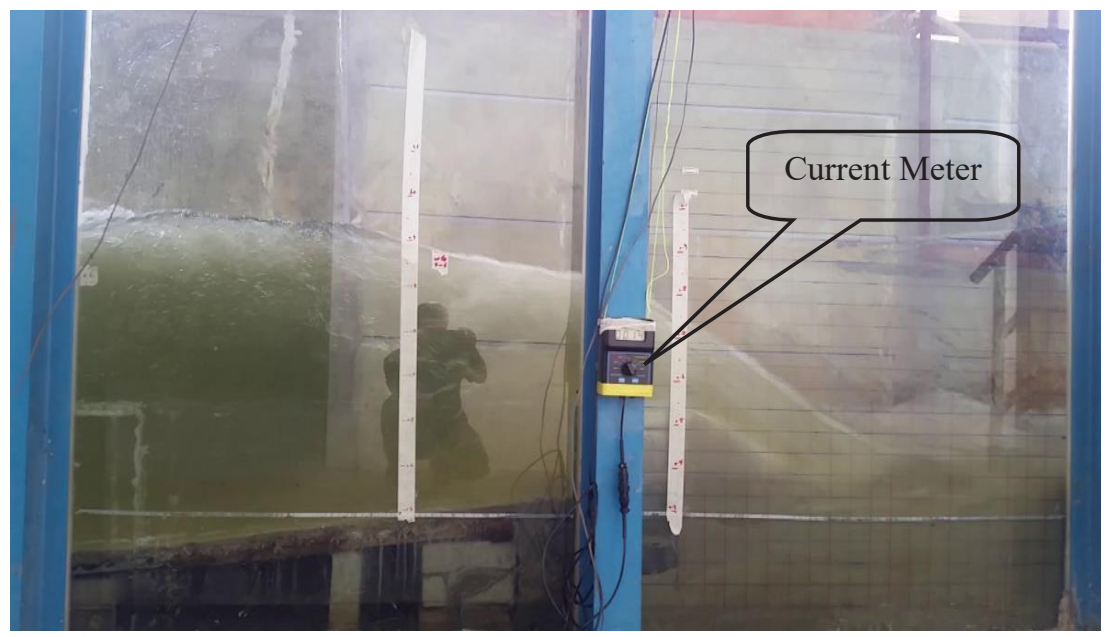

Fig.4. Typical overtopping flow 
The Vectrino Plus software was used to read the data from the device, then the data was converted to Excel sheet file for refining and analyzing. The experiments were achieved for low, medium, and high freeboard conditions as per the arrangements explained in Table 1 with three times repetition for each case. The required measurements to draw the scour profile was conducted on the landward side of the seawall for each case after allowing for water to drain totally from the scour zone. One of the main difficulties we have met in this study was the very long drain time of the water after each run. Part of the water was pumped from a point far enough from the scour zone to keep the soil undisturbed by the pump, and the remaining water was allowed to drain for one day before taking the scour measurements.

After finishing the measurements for scour, the scour zone refilled again with the same type of soil and leveled at the same level as can as possible for all the experiments. A representative sample of soil was taken for sieve analysis to determine some soil properties as shown in Figure 5.

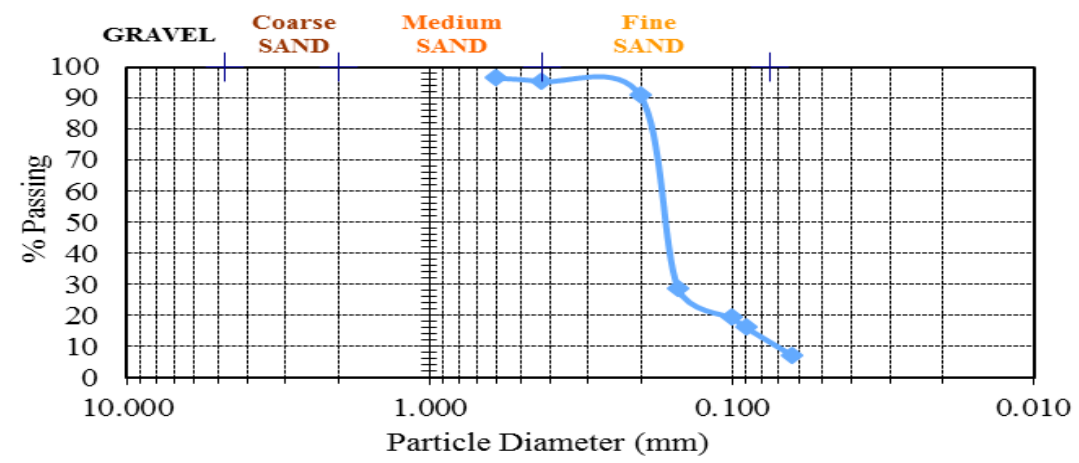

Fig. 5. Grain size distributions of the soil

\section{Results}

The flow process during testing was complicated and difficult to record and analyze due to the very short time of recording data and generation of the backflow. Once the gate is opened the flow takes 3-5 seconds to hit the seawall, overtopping and backflow generated as illustrated in Figure 6. The measured flow parameters for the three flow conditions and related maximum scour depths generated at the landward toe of the seawall are summarized in Table 2 in prototype scale. 


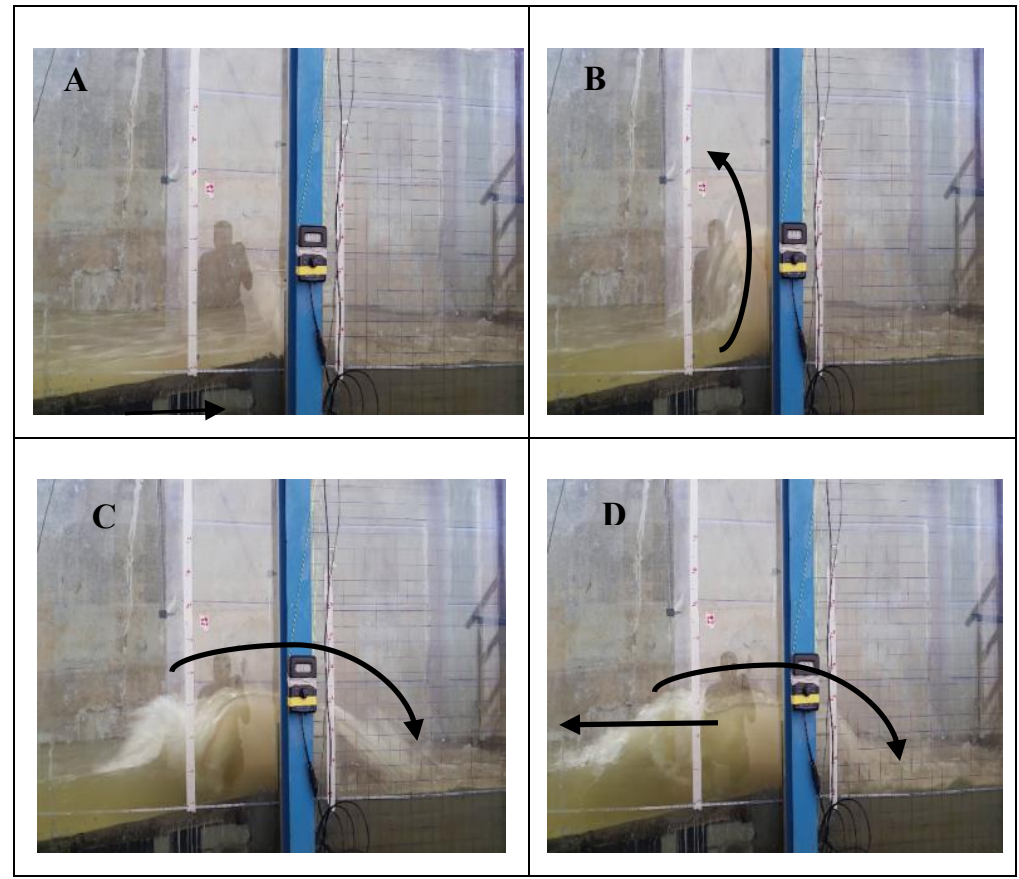

Fig.6. Flow process at the seawall for test conditions T1 A- Flow approaching the wall B- Water splashing over the wall (impulsive) C- Overtopping D- Backflow generating

Table 2. Summary of the maximum values of the hydraulic parameters for all tests conditions

\begin{tabular}{|c|c|c|c|c|c|c|}
\hline $\begin{array}{c}\text { Flow } \\
\text { conditions }\end{array}$ & $\begin{array}{c}\text { Max } \\
\text { Incident } \\
\text { bore } \\
\text { velocity, } \\
\text { Vb } \\
(\mathrm{m} / \mathrm{s})\end{array}$ & $\begin{array}{c}\text { Max. } \\
\text { overtopping } \\
\text { velocity, } \\
\text { Vo } \\
(\mathrm{m} / \mathrm{s})\end{array}$ & $\begin{array}{c}\text { Max } \\
\text { Incident } \\
\text { bore } \\
\text { height, } \\
\text { Hb } \\
(\mathrm{m})\end{array}$ & $\begin{array}{c}\text { Max. } \\
\text { overtopping } \\
\text { flow height, } \\
\text { Ho } \\
(\mathrm{m})\end{array}$ & $\begin{array}{c}\text { Max. } \\
\text { scour } \\
\text { depth, } \\
\text { Ds } \\
(\mathrm{m})\end{array}$ & $\begin{array}{c}\text { Max. } \\
\text { scour } \\
\text { length, } \\
\text { Ls } \\
(\mathrm{m})\end{array}$ \\
\hline $\begin{array}{c}\text { Low } \\
\text { depth } \\
\text { (T1) }\end{array}$ & 7.1 & 0.22 & 3.8 & 1.2 & 1.16 & 8 \\
\hline $\begin{array}{c}\text { Medium } \\
\text { depth } \\
\text { (T2 })\end{array}$ & 8.1 & 3.98 & 8.6 & 4.8 & 2.34 & 24 \\
\hline $\begin{array}{c}\text { High } \\
\text { depth } \\
\text { (T3 })\end{array}$ & 9.3 & 5.68 & 11.8 & 6 & 2.38 & 37 \\
\hline
\end{tabular}

\section{Discussion}

In this section the scour measurements and the effects of the parameters on the scour depth generated at the landward side of the seawall were presented and discussed separately including; initial water depth, incident bore height, incident bore velocity, and the overtopping flow velocity. 


\subsection{Initial water depth upstream of the seawall.}

The effects of the initial upstream water depth on the scour profile are shown in Figure 7. It is clear from the figure that the difference in the maximum scour depth and length between low and medium depth conditions are significant and the difference of maximum scour length between medium and high depth conditions are significant, but the difference in the scour depths are insignificant.

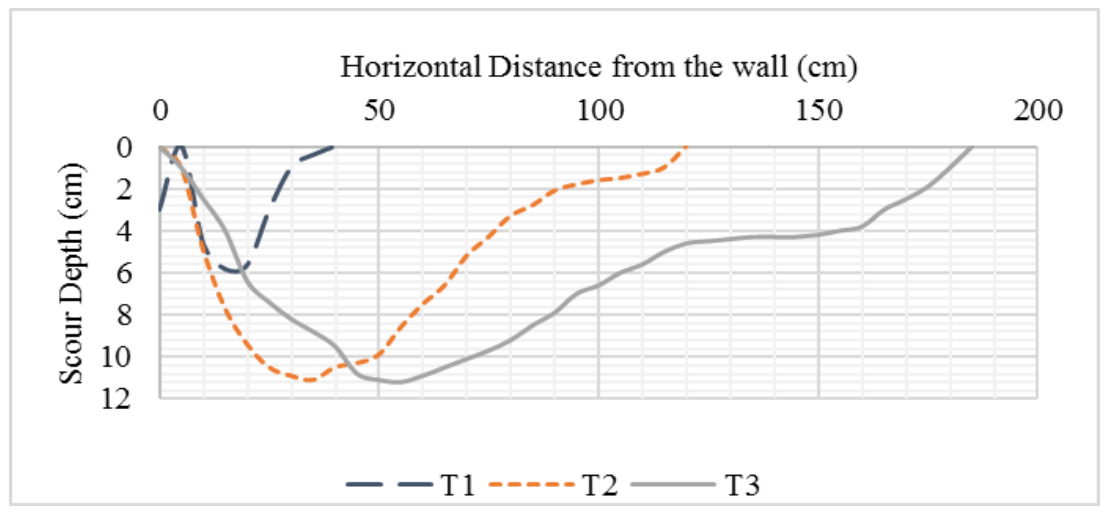

Fig. 7. Measured scour profiles for all tests conditions

The graph in Figure 8 shows the non-dimensional relationship between the seaward initial water level represented by the relative freeboard $(\mathrm{Rc} / \mathrm{hw})$ and the generated maximum scour depth due to tsunami bore represented by the relative scour (Ds/hw), where $\mathrm{Rc}$ is the difference in elevations between the crest of the wall and the seaward initial water level, and hw is the seawall height. From the graph, it is found that there is a reasonable negative relationship exists with the correlation factor equal to 0.775 obtained from the correlation analysis. The negative trend of the relationship can be interpreted that, in case of low initial water depth (or high freeboard) that means more flow resistance and more energy dissipation due to high freeboard which leads to low overtopping discharge then low scour depth.

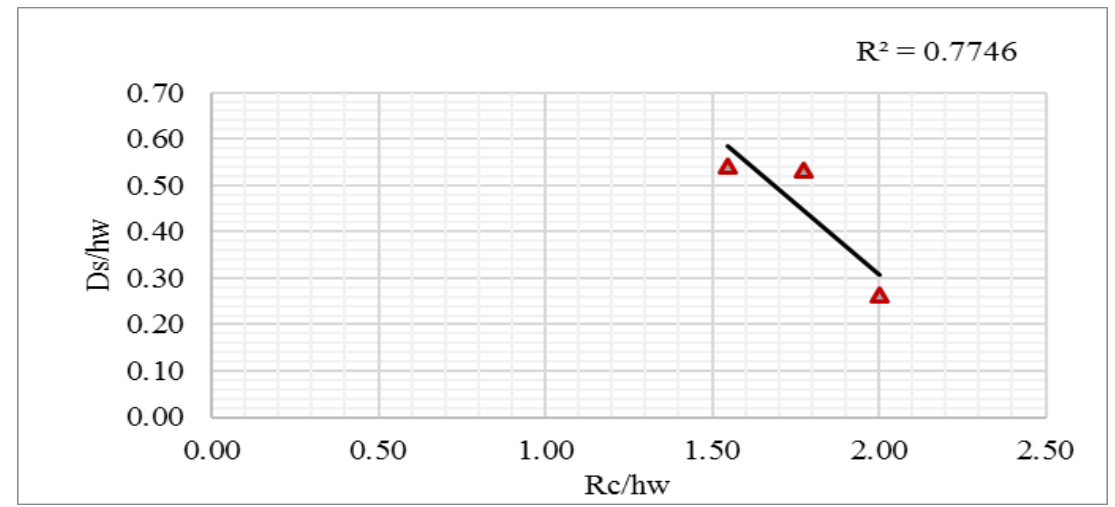

Fig. 8. Non-dimensional relationship between the seaward initial water level and the maximum scour depth generated 


\subsection{Incident bore height $\mathrm{Hb}$}

A non-dimensional relationship between the incident bore height $\mathrm{Hb}$ and the generated maximum scour depth is shown in Figure 9. The graph shows that there is a positive relationship exists with a correlation factor equal to 0.863 .

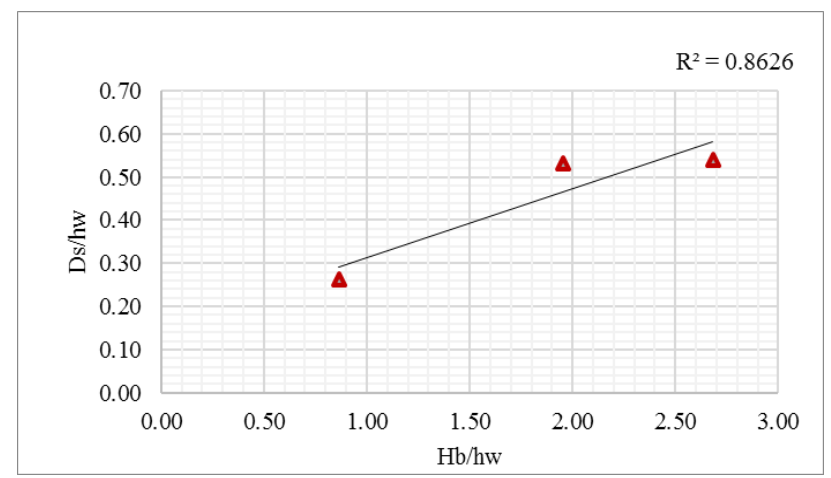

Fig. 9. Non-dimensional relationship between the incident bore height and the maximum scour depth generated

\subsection{Incident bore Froude number Fb}

The Froude Number $F_{b}=\frac{v}{\sqrt{g H_{b}}}$ was used as a representative dimensionless quantity of the incident bore velocity. The non-dimensional relationship between the Froude number of the incident tsunami bore and the maximum generated landward scour depth is shown in Figure 10. The graph revealed that, a strong negative relationship exists with a correlation factor equal to 0.992. By referring to the experimental results listed in Table 2 we observe that, if the incident bore velocity $\mathrm{Vb}$ increased the maximum scour depth is increased, but by referring to the graph in Figure 10 the negative trend for this relationship is related to the calculated values of Froude Number for these experimental conditions or may be the flow states associated with different value of Froude Number. For instance, if the Froude Number is 1 or more the flow is critical with high flow velocity and relatively small flow depth. Generally, the process is complicated and needs more studies and larger number of observations for verification and discussing. 


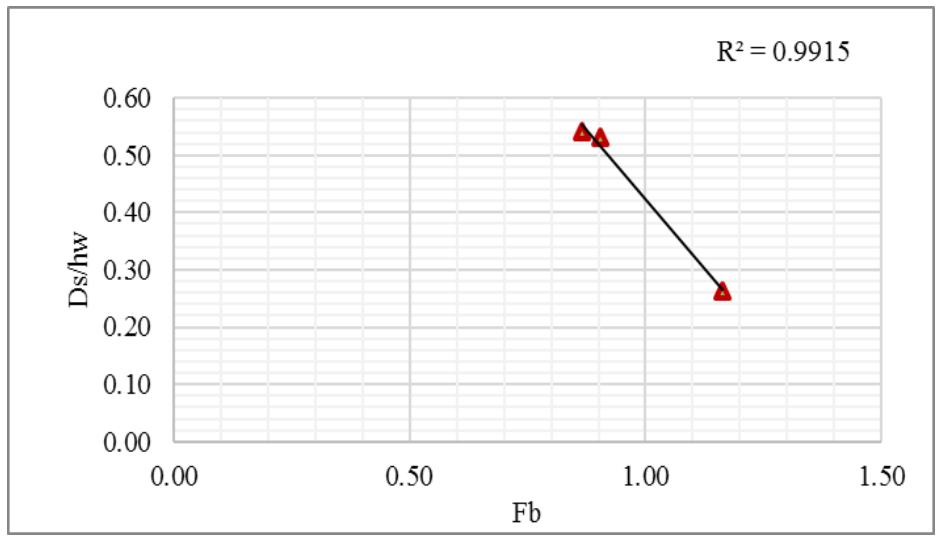

Fig. 10. Nondimensional relationship between the Froude number of the incident bore and the scour depth

\subsection{Overtopping flow velocity}

The Froude Number $F_{o}=\frac{v}{\sqrt{g H_{o}}}$ was used as a representative dimensionless quantity of the overtopping bore velocity. The non-dimensional relationship between the Froude number of the overtopping tsunami bore and the maximum generated landward scour depth is shown in Figure 11. The graph showed that a strong positive relationship is exists with a correlation factor is equal to 0.961 .

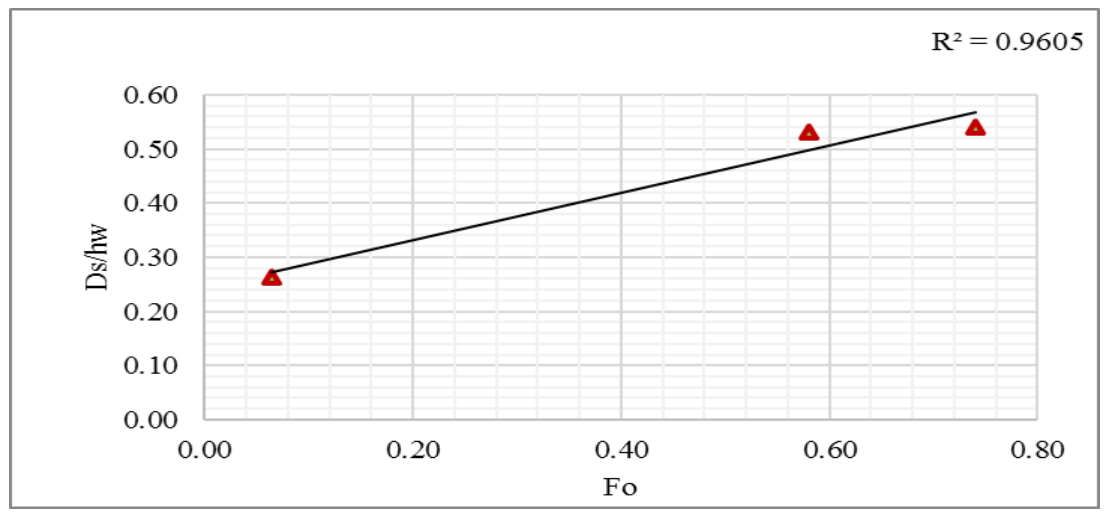

Fig.11. Nondimensional relationship between the Froude number of the overtopping tsunami bore and the scour depth

\section{Conclusions}

The experiments were conducted to investigate the scour profile generated by tsunami bore at the landward toe of the seawall for three different cases of initial depth conditions. It is found that the scour depth and length in case of low depth (high freeboard) condition are very small compared with that in the medium and high conditions, but by comparing between medium and high conditions the scour depths are not significantly different and the scour lengths are significantly different as clear from Figure 7. 
By investigating the strength of the relation between the relative scour depth generated at the landward toe of the seawall due to tsunami and the parameters; relative freeboard ( Rc/hw), incident bore height $\mathrm{Hb}$, Froude number of the incident tsunami bore $\mathrm{Fb}$, and Froude number of the overtopping flow Fo, it is found that the strongest relation exists with the Froude number $\mathrm{Fo}$ and $\mathrm{Fb}$ with correlation factors of 0.961 and 0.992 respectively. The importance of this study arise from the observation of the strength of relationship between Froude number of the bore like tsunami and the scour depth at the landward toe of the seawall which reported as the most cause of the coastal defence structure failure, and further studies required to use the Froude number in the prediction of maximum scour depth induced at the landward toe of the seawall due to tsunami.

\section{References}

1. F. Kato, Y. Suwa, K. Watanabe, and S. Hatogai, "Mechanisms of coastal dike failure induced by the Great East Japan Earthquake Tsunami," Coast. Eng. Proc., 1, 33, 1-9, (2012).

2. T. Tomiczek, A. Prasetyo, N. Mori, T. Yasuda, and A. Kennedy, "Physical modelling of tsunami onshore propagation, peak pressures, and shielding effects in an urban building array," Coast. Eng., 117, 97-112, (2016).

3. H. Park, D. T. Cox, and A. R. Barbosa, "Comparison of inundation depth and momentum fl ux based fragilities for probabilistic tsunami damage assessment and uncertainty analysis," Coast. Eng., 122, 10-26, (2017).

4. M. J. Briggs, H. Yeh, and D. T. Cox, "Physical Modeling of Tsunami Waves," in Handbook of Coastal and Ocean Engineering, Gulf Professional Publishing, 10731105, (2009).

5. T. Rossetto, W. Allsop, I. Charvet, and D. I. Robinson, "Physical modelling of tsunami using a new pneumatic wave generator," Coast. Eng., 58, no. 6, 517-527, (2011).

6. T. Shimozono and S. Sato, "Coastal vulnerability analysis during tsunami-induced levee over fl ow and breaching by a high-resolution fl ood model," Coast. Eng., 107, 116-126, (2016).

7. M. P. Jayaratne et al., "Failure Mechanisms and Local Scour at Coastal Structures Induced by Tsunami," Coast. Eng. J., 58, no. 4, 38, (2016). 